\title{
Promotion of Circular Economy: Steelwork Dusts as Secondary Raw Material in Conventional Mortars ${ }^{\dagger}$
}

\author{
Angélica Lozano-Lunar 1, Auxi Barbudo 1, José María Fernández ${ }^{2, *}$ and José Ramón Jiménez 1,* \\ 1 Construction Engineering Area, EPS of Belmez, University of Córdoba, 14240 Córdoba, Spain; \\ angelica.lozano@uco.es (A.L.-L.); abarbudo@uco.es (A.B.) \\ 2 Inorganic Chemistry Area, EPS of Belmez, University of Córdoba, 14240, Spain \\ * Corresponding authors: um1feroj@uco.es (J.M.F.); jrjimenez@uco.es (J.R.J.); \\ Tel.: +34-618-808-043 (J.M.F.); +34-667-524-702 (J.R.J.) \\ + Presented at Environment, Green Technology and Engineering International Conference (EGTEIC 2018), Caceres, \\ Spain, 18-20 June 2018.
}

Published: 22 October 2018

\begin{abstract}
Among the actions proposed by the European Union for the implementation of Circular Economy is the use of waste as a secondary raw material (SRM). During the fusion of the scrap, a steel dust is generated, named Electric Arc Furnace Dust (EAFD). The EAFD is composed mainly of potentially leachable heavy metals, so is classified as "hazardous" waste. Around the world, approximately $70 \%$ of this waste is deposited in landfills, with a previous treatment through cement-based materials to prevent the metals' mobility. However, this action is not in accordance with the Circular Economy concept due to the greater use of resources and the loss of deposited metals. The present investigation analyses the use of EAFD as SRM in conventional mortar production for its use as a construction material. Different substitution percentages $(25 \%, 50 \%$ and $100 \%)$ were used replacing siliceous filler by EAFD. The investigation analysed the behaviour of conventional mortars by tests of workability, compressive strength, water absorption by capillarity and leaching behaviour in granular and monolithic state. The results obtained indicate a slight improvement in mechanical behaviour with the incorporation of EAFD, the reason why its use as SRM in conventional mortars would benefit the construction industry and would encourage the Circular Economy. From an environmental point of view, the mechanisms of $\mathrm{Pb}$ fixation should be improved in granular state.
\end{abstract}

Keywords: steelwork dusts; secondary raw material; construction material

\section{Introduction}

One of the actions proposed by the European Union for implantation of Circular Economy [1] underlines the use of waste as secondary raw material (SRMs). This initiative will give a second life to waste that is initially destined for landfills. During the production of steel, the fusion of the scrap causes the volatilisation of metals, such as $\mathrm{Zn}, \mathrm{Pb}$, Fe or $\mathrm{Cd}$, that subsequently react with oxygen condensed into solid particles [2]. These particles are steelwork dust waste and they are commonly named Electric Arc Furnace Dust (EAFD). Due to the leachability of the metals contained in EAFD, approximately 70\% of this waste, worldwide, is deposited in landfills, with a previous treatment through cement-based materials for avoiding metal mobility [3]. Stabilization/Solidification (S/S) techniques through cement-based materials have been proven to be especially suitable for heavy metal immobilisation [4]. Therefore, $S / S$ is the most common technique in EAFD management. However, this action is not in accordance with the Circular Economy concept due the higher use and cost of resources associated with the treatment and the loss of deposited metals. The evaluation of EAFD through construction materials has been widely studied [2,5,6]. The EAFD addition to cement pastes causes a hydration delay, which incurs an increase in the setting time and the workability of the mixture [5]. Despite this delay, there are cases in which the compressive strength improves with EAFD with respect to the reference monolith [7]. From an environmental point of view, the metal leaching contained in EAFD should 
be evaluated, whether the waste is managed by landfill [8] or incorporated into a construction material [6]. The present investigation analyses the viability of using a steelwork dust (EAFD) as secondary raw material in conventional mortar production studying mechanical properties and leaching behaviour of mortars.

\section{Experimental}

Mortar production was carried out using cement CEMI/52.5 R (CEM), siliceous filler (SF) and siliceous natural sand (NS). The design of these mixtures consisted of substituting the SF by EAFD in different percentages of weight $(0 \%, 25 \%, 50 \%$ and $100 \%)$. The control mortar was named M0 and mortars with EAFD content were referred to as M25, M50 and M100. For each mix, cylindrical specimens $(80 \mathrm{~mm}$ in high and 40 $\mathrm{mm}$ in diameter) were manufactured and cured in a climatic chamber at $20 \pm 2{ }^{\circ} \mathrm{C}$ and $95 \pm 5 \%$ until tested time (28 days). The experimental programme on mortars was as follows: 3 repetitions were used to analyse the workability (UNE-EN 1015-9:2000), 3 specimens were used to determine the compressive strength (X31212:2011), 3 specimens were used to evaluation of water absorption by capillarity (UNE-EN 1015-18) and 6 specimens were used to develop the environmental assessment of the EAFD. Three specimens were used according to the compliance test (UNE-EN 12457-4:2003) for analysing the leaching behaviour of mortars with EAFD in granular state, and 3 specimens were studied according to the tank leaching test (XP X31-211:2012) for evaluating the leaching release of monoliths after the treatment of waste in a cementitious material. The leaching results, in granular and monolithic state, were compared with the "Non-Hazardous" limit of the EU Decision [9] (Table 1).

Table 1. Legal limit "Non-Hazardous" of EU Council Decision [9] to classify a waste as hazardous.

\begin{tabular}{ccccccccccccc}
\hline Components Concentration & $\mathbf{C r}$ & $\mathbf{N i}$ & $\mathbf{C u}$ & $\mathbf{Z n}$ & $\mathrm{As}$ & $\mathrm{Se}$ & $\mathbf{M o}$ & $\mathbf{C d}$ & $\mathbf{S b}$ & $\mathbf{B a}$ & $\mathbf{H g}$ & $\mathbf{P b}$ \\
\hline (mg/kg dry matter) & 10 & 10 & 50 & 50 & 2 & 0.5 & 10 & 1 & 0.7 & 100 & 0.2 & 10 \\
\hline
\end{tabular}

\section{Results and Discussion}

The mortar characterization results are shown in Table 2.

Table 2. Mortar characterization results.

\begin{tabular}{|c|c|c|c|}
\hline Mortar & Workability (min) & $\begin{array}{c}\text { Compressive Strength } \\
(\mathrm{MPa})\end{array}$ & $\begin{array}{l}\text { Water Absorption by Capillarity } \\
\left(\mathrm{Kg} / \mathrm{m}^{2} \cdot \mathrm{min}^{0.5}\right)\end{array}$ \\
\hline M0 & 105.2 & 33.91 & 0.17 \\
\hline M25 & $251.4 \uparrow$ & $38.21 \uparrow$ & $0.08 \downarrow$ \\
\hline M50 & $2333.6 \uparrow$ & $38.87 \uparrow$ & $0.08 \downarrow$ \\
\hline M100 & $5748.1 \uparrow$ & $35.65 \uparrow$ & $0.13 \downarrow$ \\
\hline
\end{tabular}

Workability increases with greater EAFD content. The increase in workability showed a delay in hydration setting time which is generally caused by the Zn content of EAFD, exactly for the formation of a coating on the cement particles [5]. The compressive strength results show an improvement in the mechanical behaviour when EAFD is incorporated into the mortars. Balderas et al. [5] observed that the cement mixed with $2 \%$ and $5 \%$ of EAFD had greater compressive strengths than cement not mixed with waste. This phenomenon was explained by the nanometric size of particles of EAFD that reinforced the matrix. In the present investigation, the improvement of the mechanical behaviour of mortars with EAFD with respect to M0, indicates that the substitution of $100 \%$ of SF is viable in mechanical terms. The smaller particle size of EAFD (with maximum size in 0.3 and $3 \mu \mathrm{m}$ ) compared to $S F$ (with maximum size in $20 \mu \mathrm{m}$ ) favours the filling of internal voids, increasing the compressive strengths of mortars. When EAFD was incorporated in mortars a decrease in water absorption by capillarity was observed. This trend was related to mechanical behaviour of mortars. Mortars with better compressive strengths recorded the lowest values of water absorption by capillarity. Regarding to the leaching behaviour, in monolithic state (Figure 1), all elements kept below the limit in all mortars except for Pb in M100 with a value slightly above the limit of $11.66 \mathrm{mg} / \mathrm{kg}$. Due to this the mortars M25 and M50 were classified as "Non-Hazardous" and the M100 as "Hazardous". The monoliths formed by the cement-based materials kept the element levels below the limit by up to $50 \%$, although the 
leaching is chemically favourable. Authors such as Laforest et al. [10] detected that the alkaline $\mathrm{pH}$ environment of monolithic cement-based samples favours $\mathrm{Pb}$ solubility. $\mathrm{Pb}$ showed a release higher than the limit for all mortars in granular state (Figure 2). Because of the $\mathrm{Pb}$ release, all mortars in granular state were classified as "Hazardous". The values reached by the mortars during the compliance test favour greater $\mathrm{Pb}$ leaching compared to the tank leaching test. In addition, the larger contact surface in the compliance test encourages higher releases. The results are in accordance with the data recorded by authors such as Ledesma et al. [8], where all the mortars in granular state were classified as "Hazardous" due to the Pb release.

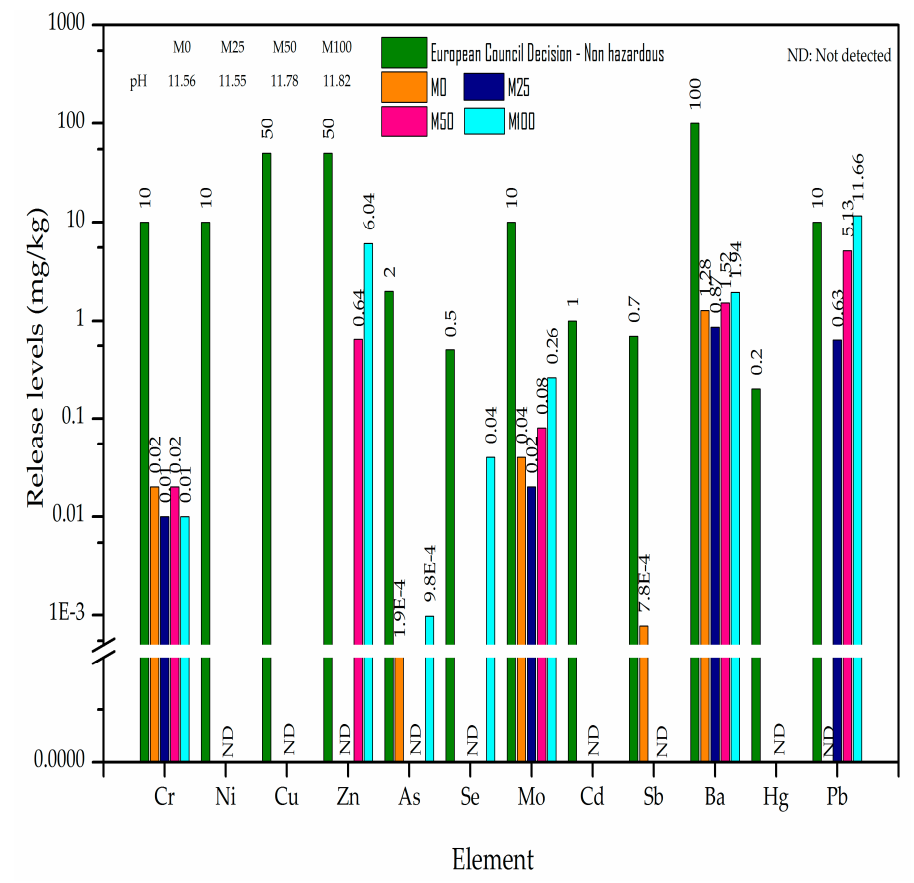

Figure 1. Release level of elements in mortars (XP X31-211).

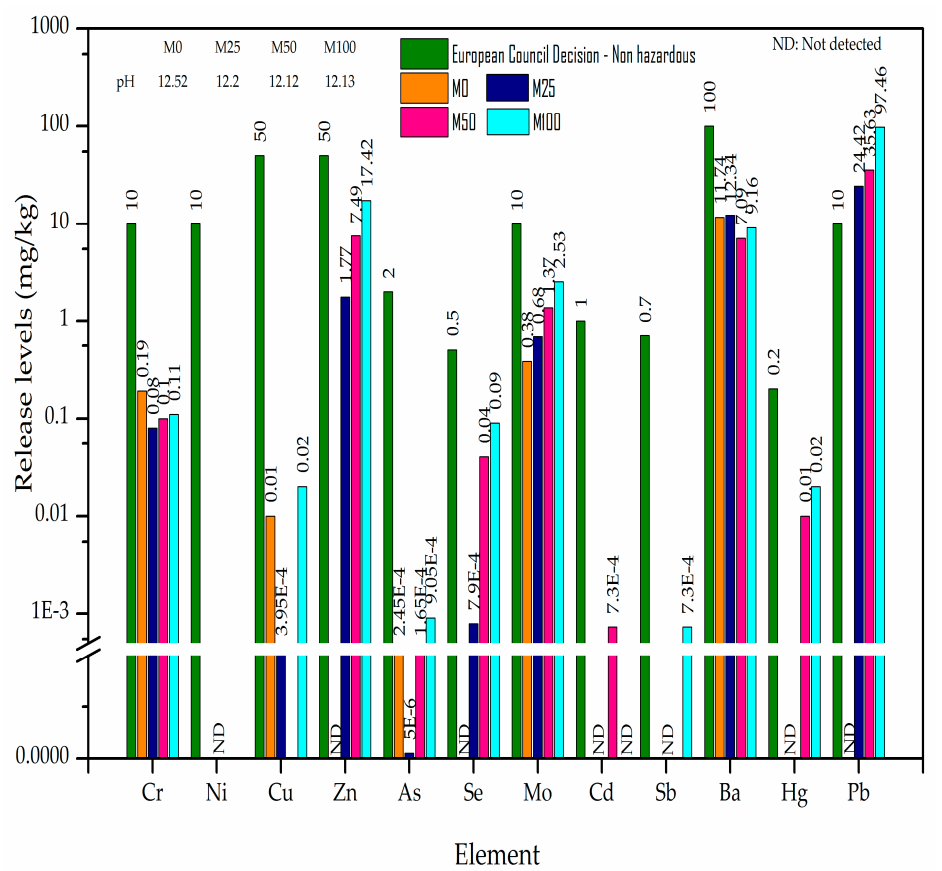

Figure 2. Release level of elements in mortars (UNE-EN 12457-4). 


\section{Conclusions}

This investigation analyses the feasibility of using a steel dust (EAFD) as a secondary raw material (SRM) in the conventional production of mortar. The workability of mortars augmented as the EAFD content increased. This delay did not adversely affect the compressive strengths, since all mortars experienced higher compressive strengths than the control mortar at 28 days of curing time. The improvement of mechanical behaviour was related to a filler effect that caused the EAFD, due to a smaller size of particles capable of filling voids. This fact was also observed in the water absorption by capillarity of mortars. According to the environmental assessment, EAFD can be incorporated into mortars up to $50 \%$ in a monolithic state. From this percentage, the $\mathrm{Pb}$ release registered did not lead to the classification of the mortars as "Non-Hazardous". In a granular state, all mortars were classified as "Hazardous" due to the content of $\mathrm{Pb}$ released. The results of the present investigation indicate viability of the use of EAFD as SRM, facilitating implementation of the Circular Economy concept, although $\mathrm{Pb}$ control tools in granular mortars should be investigated and improved.

Author Contributions: J.R.J. and J.M.F. conceived and designed the experiments; A.L.-L. and A.B. performed the experiments; J.R.J., J.M.F., A.L.-L. and A.B. analysed the data; A.L.-L. wrote the paper.

Acknowledgments: This investigation was partly supported by the Andalusian Regional Government (Research Groups TEP-227 and FQM-391) and by the XXI Own Program for the Promotion of Research at the University of CórdobaModality 4.2. (FEDER). The authors would like to thank the public company ENRESA for financial support this research via project (035-ES-IN-0140). A. Lozano-Lunar also acknowledges funding from MECD-Spain (http://www.mecd.gob.es/ educacion-mecd/) FPU14/05245. The authors wish to thank the staff at the Central Research Support Service (SCAI) for the assistance and technical support.

Conflicts of Interest: The authors declare no conflict of interest.

\section{References}

1. Report from the Commission to the European Parliament, the Council, the European Economic and Social Committee and the Committee of the Regions on the Action Plan for the Circular Economy; European Commission: Brussels, Belgium, 2017.

2. Issa, H.; Korac, M.; Gavrilovski, M.; Pavlovic, M.; Kamberovic, Z. Possibility of carbon steel eafd solidification/stabilization in concrete. Rev. Chim. 2012, 63, 1008-1012.

3. Maslehuddin, M.; Awan, F.R.; Shameem, M.; Ibrahim, M.; Ali, M.R. Effect of electric arc furnace dust on the properties of opc and blended cement concretes. Constr. Build. Mater. 2011, 25, 308-312.

4. Chen, Q.Y.; Tyrer, M.; Hills, C.D.; Yang, X.M.; Carey, P. Immobilisation of heavy metal in cement-based solidification/stabilisation: A review. Waste Manag. 2009, 29, 390-403.

5. Balderas, A.; Navarro, H.; Flores-Velez, L.M.; Dominguez, O. Properties of portland cement pastes incorporating nanometer-sized franklinite particles obtained from electric-arc-furnace dust. J. Am. Ceram. Soc. 2001, 84, $2909-2913$.

6. Cholake, S.T.; Farzana, R.; Numata, T.; Sahajwalla, V. Transforming electric arc furnace waste into value added building products. J. Clean. Prod. 2018, 171, 1128-1139.

7. Alizadeh, M.; Momeni, M. The effect of the scrap/dri ratio on the specification of the eaf dust and its influence on mechanical properties of the concrete treated by its dust. Constr. Build. Mater. 2016, 112, 1041-1045.

8. Ledesma, E.F.; Jimenez, J.R.; Ayuso, J.; Fernandez, J.M.; de Brito, J. Experimental study of the mechanical stabilization of electric arc furnace dust using fluid cement mortars. J. Hazard. Mater. 2017, 326, 26-35.

9. EU. European Council Decision for the Acceptance of Waste at Landfills. 2003. Available online: https://eurlex.europa.eu/legal-content/ES/TXT/PDF/?uri=CELEX:32003D0033\&from=GA (accessed on 16 October2018).

10. Laforest, G.; Duchesne, J. Investigation of stabilization/solidification for treatment of electric arc furnace dust: Dynamic leaching of monolithic specimens. Cem. Concr. Res. 2007, 37, 1639-1646.

(C) 2018 by the authors. Licensee MDPI, Basel, Switzerland. This article is an open access article distributed under the terms and conditions of the Creative Commons Attribution (CC BY) license (http://creativecommons.org/licenses/by/4.0/). 